\title{
Spinous process metastasis in an EGFR- mutated lung adenocarcinoma patient
}

\author{
Metastáza spinálního procesu u pacienta s EGFR mutovaným \\ plicním adenokarcinomem
}

\author{
Okauchi S., Satoh H. \\ Division of Respiratory Medicine, Mito Medical Center, University of Tsukuba-Mito Kyodo General Hospital, Japan
}

In lung cancer, the mechanism of carcinogenesis has been elucidated, and several driver genes have been discovered [1]. Drugs that respond specifically to them have come to be used in clinical settings [1]. The epidermal growth factor receptor (EGFR) gene mutation is one of such driver genes. Non-small cell lung cancer (NSCLC) patients with control of bone metastases by EGFR tyrosine kinase inhibitors (EGFR-TKIs) have been reported [2]. NSCLC can metastasize to rare sites. We show herein a case with metastasis to thoracic spinous process from EGFR-mutated NSCLC.

A 79-year-old woman was referred to our hospital because of a chest abnormal opacity detected via annual mass screening. Chest CT showed a nodule in the upper right lobe and an osteolytic change in the 5 th thoracic spinous process, suggesting the presence of bone metastasis (Fig. 1A). In fluorode- oxyglucose-positron emission tomography, uptake was observed in the $5^{\text {th }}$ thoracic spinous process (Fig. 1B). The tissue obtained by bronchoscopy revealed EGFR-mutated lung adenocarcinoma. A third-generation EGFR-TKI osimertinib - was administered. CT performed 2 months after the start of osimertinib treatment confirmed improvement in the primary lesion and osteolytic changes in the $5^{\text {th }}$ thoracic spinous process.

Bone metastases are common in lung cancer. Among them, metastases to the thorax are frequently observed. Pain is a most important clinical problem with bone metastases. In addition, metastases to the weight-bearing bones cause dysfunction. As a result, activities of daily living are restricted and performance status of the patient is reduced. In metastasis to the vertebrae, metastasis to the vertebral body is frequent. Me-

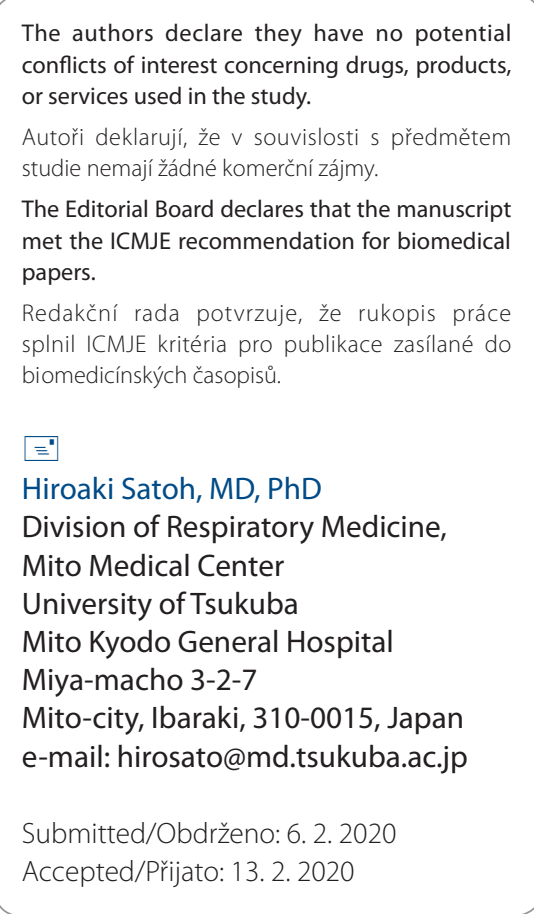

doi: $10.48095 /$ ccko2021166
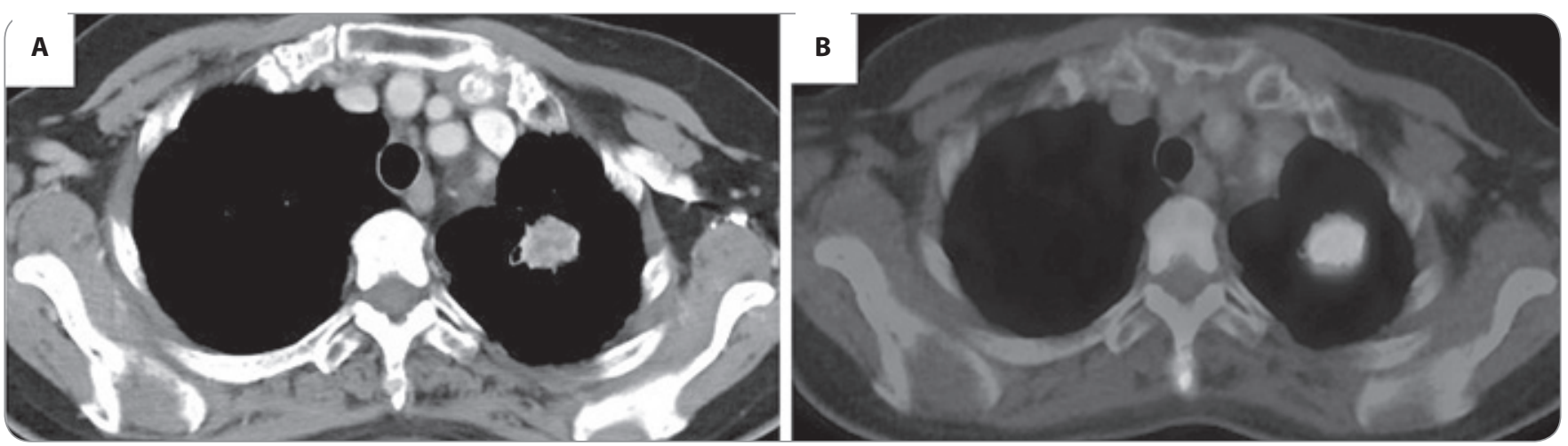

Fig. 1. Chest CT showed a nodule in the upper right lobe and an osteolytic change in the $5^{\text {th }}$ thoracic spinous process (A). In fluorodeoxyglucose-positron emission tomography, uptake was observed both in the primary nodule and in the $5^{\text {th }}$ thoracic spinous process (B). 
tastasis to the vertebral body is accompanied by dysfunction if a fracture occurs. Invasion into the intervertebral foramen and spinal cord cavity results in severe neuropathy. Therefore, it is necessary to treat such bone metastases as soon as they are found. On the other hand, metastasis to transverse processes and spinous processes is not an oncology emergency unless it extends to the vertebral body, intervertebral foramen, and spinal cord cavity. Therefore, the invasion of metastatic lesion to these sites must be prevented.

In this patient, solitary metastasis to the thoracic spinous process was confir- med. Metastasis to the spinous process is extremely rare, and to the best of our knowledge, only three cases have been reported; one from rectal cancer and other two from lung adenocarcinoma [3-5]. In addition to irradiation, for patients who carry a driver gene treatable with specific therapeutic drugs, therapeutic agents for driver genes such as EGFR-TKI might help control bone metastasis to rare sites.

\section{Authors' contributions}

HS designed the study, SO and HS collected the data, $\mathrm{SO}$ and HS analyzed the data, HS prepared the manuscript. All authors approved the final version for submission.

\section{References}

1. Malapelle U, Muscarella LA, Pisapia P et al. Targeting emerging molecular alterations in the treatment of non-small cell lung cancer: current challenges and the way forward. Expert Opin Investig Drugs 2020; 29(4): 363-372. doi: 10.1080/13543784.2020.1732922

2. Zampa G, Moscato M, Brannigan BW et al. Prolonged control of bone metastases in non-small-cell lung cancer patients treated with gefitinib. Lung Cancer 2008; 60(3): 452-454. doi: 10.1016/j.lungcan.2007.11.002.

3. Davis MA, Taylor JA. A case of vertebral metastasis with pathologic c2 fracture. J Manipulative Physiol Ther 2007; 30(6): 466-471. doi: 10.1016/j.jmpt.2007.05.001

4. Demirçay E, Civelek R, Demiralay E. Solitary spinous process metastasis: a case report. Eklem Hastalik Cerrahisi 2013; 24(1): 58-61. doi: 10.5606/ehc.2013.14.

5. Patil AK, Aditya PC, Jadhav S et al. Unusual presentation of metastasis in spine. [online]. Available from: http:// www.iosrjournals.org/iosr-jdms/papers/Vol13-issue9/ Version-1/N013916873.pdf. 